\title{
AS LEIS DE ANISTIA BRASILEIRA (1979) E ARGENTINA (1983) EM PERSPECTIVA COMPARADA
}

\author{
Alexandre Garrido da Silva* \\ Carlos Eduardo Artiaga Paula** \\ Júlia Machado Dias ${ }^{* * *}$
}

Sumário: 1 Introdução; 2 Análise comparada entre as ditaduras no Brasil e na Argentina; 2.1 Diferenças e semelhanças do processo ditatorial argentino e brasileiro; 2.2 Comparação da Lei de Anistia em ambos os países; 3 Poder Judiciário e (in)constitucionalidade da Lei de Anistia - análise da estrutura, do funcionamento e das prerrogativas do Poder Judiciário de ambos os países; 4 Decisão dos poderes judiciários brasileiro e do argentino sobre a constitucionalidade da Lei de Anistia; 5 Conclusão.

Resumo: Este artigo aborda a justiça de transição brasileira e argentina por meio da análise de suas respectivas Leis de Anistia e de seus contextos de criação. Essa análise faz-se necessária para entender a razão dos dois processos darem-se de maneiras tão díspares, em especial no que se refere à punição dos militares envolvidos no regime e em suas atrocidades. Será discutida, ao longo do texto, a legitimidade que a ditadura brasileira obteve perante a sociedade e o uso dela para propiciar uma transição controlada, ao contrário do que se percebe no caso argentino. Nesse sentido, o presente estudo mostra-se como uma demonstração do processo de redemocratização brasileiro, que perpassa, ainda, os dias de hoje e precisa do reforço da memória nacional para que se consolide em sua totalidade.

Palavras-chave: Ditadura. Lei de Anistia. Argentina. Brasil. Justiça de transição.

\footnotetext{
Doutor e Mestre em Direito Público pela Universidade do Estado do Rio de Janeiro. Bacharel e licenciado em Ciências Sociais pela UFRJ. Bacharel em Direito pela UERJ. Professor Adjunto da Faculdade de Direito da Universidade Federal de Uberlândia. Docente do corpo permanente do Curso de Mestrado em Direito Público da FADIR/UFU.

** Mestrando em Direito Público pela Universidade Federal de Uberlândia. Bacharel em Direito pela Universidade Federal de Uberlândia. Advogado atuante nas áreas cível e administrativo. Servidor público na Universidade Federal de Uberlândia. Especialista em Direito Processual Civil pela Universidade Anhanguera - Uniderp.

**a Graduanda em Relações Internacionais pelo Instituto de Economia da Universidade Federal de Uberlândia.
} 


\section{Introdução}

No Brasil, em $1^{\circ}$ de abril de 1964, militares marcharam, com viaturas e carros de combate, no interesse de tomar o poder do país. No dia seguinte, o Congresso Nacional decretou vaga a presidência da República, dando posse ao presidente da Câmara de Deputados, Ranieri Mazzili. Entretanto, o poder era exercido de fato por uma junta militar, formada por Artur da Costa e Silva, Francisco de Assis Correia Melo e Augusto Rademaker. Posteriormente, no dia 11 de abril, foi eleito, pelo Congresso Nacional, o marechal Humberto de Alencar Castelo Branco para exercer a presidência. (WEID, 2012)

Doze anos depois, em 24 de março de 1976, um golpe de Estado foi efetivado, também, na Argentina, mas de maneira mais incisiva. A presidenta María Estela Martínez Perón, conhecida como Isabelita Perón, foi presa em um helicóptero ao sair do palácio presidencial, em meio ao golpe de Estado orquestrado pelos chefes militares argentinos. $\mathrm{O}$ golpe obteve sucesso total sem ser necessário sequer um tiro. Em seguida, os governadores e os parlamentares foram imediatamente destituídos, e o Congresso foi fechado. Já a presidência foi assumida por uma junta militar, formada por Jorge Rafael Videla, Emilio Eduardo Massera e Orlando Ramón Agosti, chefiada pelo primeiro. (WEID, 2012)

Por essa breve análise dos respectivos golpes de Estado, percebe-se quão ostensivo foi o golpe na Argentina (presidente sequestrada no próprio Palácio Presidencial e fechamento quase imediato do Congresso Nacional), enquanto, no Brasil, houve a necessidade de mascarar tal evento para melhor cumprir o objetivo de combate à ameaça comunista, mantendose "de fachada" as instituições democráticas (tais quais o Congresso e a Constituição Federal), nos termos do texto do Ato Institucional número 1, que assim dispôs: "para demonstrar que não [pretende-se] radicalizar o processo [nomeado por eles de] revolucionário".

Em síntese, enquanto, no Brasil, as graves violações a direitos humanos eram ocultadas (ou, ao menos, buscava-se omitir essas medidas), na Argentina, essas atividades eram, desde o início da ditadura, ostensivas. Ao final do regime de exceção, com a promulgação da Lei de Anistia, o Poder Judiciário no Brasil manifestou-se favorável à promulgação da Lei, enquanto, na Argentina, essa medida legislativa foi declarada inconstitucional. Logo, neste país, foram muito mais intensas as medidas para identificar e reprimir os opositores do regime. Esse modo como a ditadura foi conduzida no Brasil e na Argentina, mesmo que sucintamente 
descrito, demonstra que são nítidas as diferenças institucionais e sociais entre os regimes militares, o que repercutiu na forma como as Leis de Anistia foram vistas e recebidas pelo Poder Judiciário.

No Brasil, a justiça de transição - processo pelo qual passam os países que enfrentaram regimes ditatoriais com graves violações às liberdades democráticas e aos direitos humanos - é extremamente defasada, em especial se comparada com a de seus vizinhos latino-americanos, sobretudo quando se depara com o pouco interesse na busca pela verdade, no resgate da memória, nas poucas indenizações das vítimas e na postura do Poder Judiciário em apoiar a Lei de Anistia, ou seja, em não punir os algozes responsáveis pelo regime de exceção. A autoanistia, realizada com a Lei 6.683/1979, "imposta" pelos próprios generais militares - executores do regime -, significou uma cultura do esquecimento e do desinteresse na revelação das circunstâncias e dos nomes dos criminosos políticos. (MEZAROBBA, 2007)

A Lei de Anistia brasileira é a única entre a de todos os países latinoamericanos que, mesmo tendo sido promulgada por um ditador - sobretudo em virtude da legitimação obtida no regime, conforme será explicitado posteriormente -, permaneceu em vigência durante e após o processo de redemocratização. Nos demais países latino-americanos, as Leis de Anistia foram e são vistas como um legado perverso que precisa ser superado.

Por outro lado, o processo de justiça de transição argentino é visto como um exemplo a ser seguido e merece, por inúmeros fatores, ser estudado em comparação com o brasileiro. Um deles é o social, representado pelo ainda presente movimento social da Praça das Mães de Maio, conhecido em todo o mundo e que obtém resultados para suas demandas na busca pela verdade e pela memória. Esse resgate da memória - intimamente ligado à construção da sociedade democrática - é de suma importância para recuperar a história, construir o presente, caminhar em direção ao futuro na consolidação do estado social democrático de direito e para reprimir a existência de regimes políticos dessa estirpe.

De forma a entender as diferenças presentes nesses dois regimes, algumas expostas acima, faz-se necessário comparar a Lei de Anistia do Brasil e a da Argentina, bem como comparar a ditadura brasileira (1964-1985) e a argentina (1976-1983) com base em critérios históricos, sociais e jurídicos, traçando semelhanças, diferenças e particularidades. Entende-se que, desse modo, será possível responder, ao final do estudo, ao questionamento do motivo pelo qual decisões divergentes foram proferidas pelo Poder Judiciário no Brasil e na Argentina quanto à constitucionalidade das respectivas Leis de Anistia. 
Assim sendo, no primeiro capítulo deste artigo serão analisadas algumas REFERÊNCIAS para compreender o modo como se deu a ditadura argentina e a brasileira como um todo, bem como suas Leis de Anistia. Posteriormente, dar-se-á a análise do Poder Judiciário nos dois países - sua estrutura, seu funcionamento e suas prerrogativas. Na última etapa, serão analisadas as decisões judiciais sobre a Lei de Anistia à luz do arcabouço teórico construído nos dois primeiros capítulos, com o objetivo de avançar na resposta do questionamento quanto às divergentes decisões do Poder Judiciário argentino e do brasileiro a respeito da constitucionalidade de suas Leis de Anistia.

\section{Análise comparada entre as ditaduras no Brasil e na Argentina}

\subsection{Diferenças e semelhanças do processo ditatorial argentino e brasileiro}

Conforme exposto no tópico anterior, o processo de tomada de poder pelos militares se deu de forma diferente em cada país, tendo sido o golpe argentino relativamente mais incisivo em comparação com o brasileiro. Entretanto, os dois regimes assemelham-se pelo amplo apoio de diversas classes no momento de ascensão ao poder, apoio esse explicado pela existência de crises políticas (representadas pela ameaça comunista, ou ao menos é assim que os militares de ambos os países desejavam representálas) e econômicas (vistas pelo alto nível de inflação e de decadência econômica).

Nas palavras de Fausto e Devoto:

o quadro é clássico: alívio pelo fim da ameaça comunista, crença na limpeza promovida contra os "maus brasileiros" - corruptos e subversivos -, que enchiam as prisões e os navios ancorados nos portos de Santos e do Rio de Janeiro; expectativa de vida melhor, sem o fantasma da inflação e os atropelos da profunda instabilidade política. (2004, p. 422)

Desse modo, pode-se dizer que, em ambos os países, o regime ditatorial foi visto pela população como medida paliativa, com a qual se objetivava efetuar reformas que representassem melhorias em termos de eficácia nos setores supracitados, como forma de possibilitar o retorno a um regime democrático. Sabe-se, entretanto, que as coisas não aconteceram exatamente assim e, mesmo tendo - ao menos em teoria - esse objetivo final em comum, os rumos que as ditaduras desses países tomaram, a partir daí, mostram-se bem díspares. 
O Brasil teve suas leis eleitorais completamente modificadas: extinguiram-se os partidos, instalando-se o bipartidarismo, e fecharam-se diversos órgãos representativos. Entretanto, mantiveram-se aspectos como a Constituição de 1946 e o Congresso Nacional. A manutenção desse aparato jurídico no regime (cuja existência é uma das maiores diferenças em relação à ditadura argentina) faz surgir um questionamento quanto à institucionalização do regime como forma de sustentar o apoio dado pelos diversos setores sociais.

Essa constante necessidade de aparentar legalidade e constitucionalidade é vista no Ato Institucional 1 - um dos atos normativos utilizados pelo regime para definir o que podia ou não ser feito -, que apresenta a ideia da necessidade de modificações legais (consequentemente, de se institucionalizar), em especial no que se refere aos poderes do(a) presidente da República, como forma de "assegurar ao novo governo a ser instituído, os meios indispensáveis à obra de reconstrução econômica, financeira, política e moral do Brasil". No texto, há inclusive uma frase específica sobre o tema, assim sendo: "A revolução vitoriosa necessita de se institucionalizar e se apressa pela sua institucionalização a limitar os plenos poderes de que efetivamente dispõe".

Fausto e Devoto (2004) dão a essa especificidade o nome de "democracia restrita", a qual representa uma democracia com salvaguardas contra a quebra da ordem pública. Para os autores, a continuidade das instituições liberais constituiu um conjunto de regras que deu estabilidade ao regime, chegando a desempenhar o papel de válvula de escape para as pressões mais políticas que sociais, mesmo com as violências e arbitrariedades. No caso argentino, além da inexistência de um mínimo de representatividade pela via parlamentar, os conflitos sociais eram latentes, em especial pela magnitude das ações da guerrilha urbana e da fragilidade institucional do regime, resultando em maior abrangência da ação repressiva no país.

Assim, na Argentina, que enfrentava grave crise econômica no contexto do golpe militar, com grande inflação, recessão e dívidas, o regime militar almejava ordem e segurança econômica, segundo Novaro e Palermo (2007), uma vez que viam na sociedade conflituosa, em que o Estado era fraco politicamente para controlar a organização trabalhadora e até empresarial, as raízes desses problemas. Por isso, os militares argentinos também se apresentaram como a solução dos problemas enfrentados pelo país no momento do golpe, por meio do chamado "Processo de Reorganização Nacional". Diferenciação essencial, entretanto, refere-se 
às práticas militares no decorrer do regime, cujos instrumentos não foram institucionalizados, caracterizando-se como "terrorismo de Estado", em razão de sua clandestinidade. Assim, toda e qualquer atividade política foi proibida, de modo que partidos e eleições passaram a não mais existir. (TRIBESS, 2012)

Um fator a ser tratado como diferencial nos dois regimes é, portanto, o sucesso econômico, que se mostra importante como forma de garantir a continuidade do apoio popular, essencial para definir os rumos do país no momento de transição política. O sucesso econômico brasileiro do período permitiu que os militares organizassem uma transição política baseada na impunidade dos responsáveis por violações dos direitos humanos no período ditatorial, que foi obtida, sobretudo, com a Lei de Anistia de 1979.

Assim, o "milagre econômico" brasileiro da década de 1970 resultou em legitimidade para o governo militar, a qual foi usada para controlar o processo de transição. Além disso, a legitimação do regime militar, resultante desse sucesso econômico, gerou euforia, sobretudo nos setores de classe média, o que ocasionou em ignorar ou ver como situações incômodas, mas inevitáveis - de importância secundária -, as violências repressivas, mesmo no momento em que estas atingiram seu ponto mais alto. (FAUSTO; DEVOTO, 2004)

$\mathrm{Na}$ Argentina, a situação foi completamente diferente, em especial pelo aumento das taxas de inflação e desemprego a partir do golpe, produzindo um descontentamento popular que retirou o controle do poder militar sobre a transição e a acelerou. Desse modo, enquanto, na Argentina, houve recusa em negociar por parte da oposição e da população, no Brasil, as eleições diretas para a presidência foram adiadas por mais quatro anos, mesmo com a forte atuação de movimentos por uma democratização mais rápida, como as "Diretas Já". (NOVARO; PALERMO, 2007; TRIBESS, 2012)

Conforme será exposto no próximo tópico, todas essas características dos respectivos regimes militares são fundamentais para entender as divergências nos processos de transição de cada país.

\subsection{Comparação da Lei de Anistia em ambos os países}

Também o contexto em que se insere a criação das Leis de Anistia tem suas singularidades em cada um dos países. Apesar de o conteúdo das leis ter notoriamente o mesmo objetivo - a impunidade dos militares -, elas foram concebidas e recebidas de maneiras diferentes em cada sociedade. 
O processo de criação da Lei de Anistia brasileira, Lei 6.683 de 28 de agosto de 1979, foi um momento de ampla participação popular. Entende-se, desse modo, que a anistia brasileira surge enquanto demanda social, o oposto do ocorrido nos demais países do Cone Sul, diferenciação fundamental para entender, mesmo que em parte, por que a justiça de transição dá-se de maneira adversa. A participação popular ocorreu, em especial, por meio do envio de emendas ao projeto, com vistas a evitar que a lei gerasse a impunidade que acabou por resultar.

Entretanto, como nenhuma delas foi aprovada, a lei foi mais benéfica aos repressores que aos oprimidos: mais que impunidade, a anistia foi usada como justificativa para encobrir graves violações de direitos humanos, sob o argumento de se evitar um revanchismo no país - argumento ainda hoje utilizado e que prejudica a recente Comissão da Verdade no cumprimento de seu papel. Mezarobba traz alguns exemplos dos argumentos usados para rejeitar as emendas apresentadas no Congresso, os quais deixam clara a forma "como o governo via a colaboração da oposição":

o conceito de anistia do ilustre senador não é o do governo nem o nosso; aceitar a data da publicação da lei seria correr um risco, pois, maus elementos poderiam ficar à espreita para, conhecida a redação final do projeto, e antes mesmo da sanção, praticarem crimes, já acobertados previamente pelo manto da lei; pelas razões já expostas em relação a outras emendas, o governo e o seu partido não concordam em anistiar pessoas condenadas por crimes contra a humanidade; o exílio foi voluntário; a lei de anistia não implica na destruição dos arquivos do país. Não estamos revogando a legislação em vigor; esta lei não tem por objetivo revogar a Lei de Segurança Nacional [...] [e, ainda, a defesa de ser] emenda "impertinente". (2003, p. 45)

Por conseguinte, mesmo com o interesse da sociedade em criar um diálogo com o governo, o texto da lei não alcançou os que verdadeiramente haviam sido prejudicados pelo regime. Conforme Mezarobba (2003), a anistia só interessou aos militares, foi uma reação à pressão que o Estado sofria pela responsabilização em virtude da morte de Vladimir Herzog um dos diversos presos políticos, cuja morte foi comprovadamente ação dos agentes do Estado, embora estes tentassem demonstrar um improvável suicídio - e representou o interesse pelo pluripartidarismo como forma de dividir a oposição. O desinteresse do governo no diálogo, evidente na votação da Lei de Anistia, mostrou-se, também, na recusa em aceitar a revisão de casos de punições administrativas e, com um discurso de defesa dos direitos humanos, no argumento de que os "terroristas" haviam praticado crimes contra a humanidade e, por isso, ficariam de fora da Lei da Anistia. 
O caso argentino não foi tão diferente no que se refere à criação da lei, consolidada na Lei de Pacificação Nacional (Lei 22.924), de 22 de setembro de 1983. Além de ser um instrumento de poder utilizado pelas Forças Armadas para reconstruir a sociedade democrática, anistiar os envolvidos politicamente no regime era essencial para acabar com a desconfiança popular em relação aos militares, tendo em vista a deslegitimidade política do regime. Também na Argentina houve mobilização social, em especial de organizações de direitos humanos, a qual não foi tão eficaz, uma vez que a lei supracitada foi sancionada da mesma forma. (MEZAROBBA, 2007)

Mezarobba (2007) aponta que as discrepâncias identificadas nesse processo transicional no Estado brasileiro, quando comparado ao Argentino, podem ser entendidas por dois aspectos: em primeiro lugar, a Lei de Pacificação Nacional, decretada pelo general Reynaldo Bignone pouco antes de a Junta Militar que governava o país deixar o poder, não havia sequer sido reivindicada e, em segundo lugar, a imediata resistência popular contra a legislação, percebida por ela como uma auto-anistia, e a rejeição de seus benefícios por presos políticos que há anos estavam encarcerados.

Nas palavras da autora, dado esse contexto, "parece natural, portanto, que a legislação nacional viesse a desempenhar papel distinto no processo de acerto de contas do Estado brasileiro pelas arbitrariedades cometidas entre 1964 e 1985" (MEZAROBBA, 2007, p. 338). Assim, em dezembro do mesmo ano de sua sanção, a lei argentina foi considerada nula ou inexistente como lei pelo presidente recém-eleito democraticamente, Raúl Alfonsín, do partido político União Cívica Radical (UCR).

Desse modo, é evidente que o regime brasileiro, por ainda dispor de certa credibilidade perante a população, conseguiu manejar de maneira mais eficiente, em seu favor, o processo de criação da lei - tal como ao longo do processo transicional. De acordo com Tribess:

os pactos efetuados nas transições normalmente se dão no intento de reduzir conflitos e competitividade, ou seja, grupos acordam em não se prejudicar. Os pactos entre militares e oposição ocorrem quando nenhum dos grupos possui força e predominância suficientes para impor ao outro seus objetivos, nem pode governar sem ter algum apoio do outro. $(2012$, p. 26)

Nesse sentido da existência de credibilidade como forma de controlar a transição, a análise de Martins (1988) vai ao encontro do argumentado na seção anterior deste artigo: o aparente sucesso econômico e institucional do regime no Brasil desarticulou a oposição e possibilitou que a transição ocorresse com maior confiança nos agentes da ditadura, que buscaram se 
legitimar eleitoralmente e mostrar que estavam agindo para preparar o país para a democracia.

Por outro lado, a notória fragilidade na Argentina, não só econômica, como também política, fez com que o regime tivesse um fim abrupto. Tal fim foi precipitado pelo episódio da Guerra das Malvinas, o qual serviu para contribuir ainda mais para a desmoralização e deslegitimação do poder militar, impedindo os militares de negociar sua saída, fato que marcou profundamente a transição para o regime democrático (FAUSTO; DEVOTO, 2004). É possível perceber isso, em especial, quando se analisa a consideração do Poder Judiciário argentino sobre todas as leis promulgadas pelos militares, quais sejam a Lei de Obediência e as Leis do Esquecimento, como sendo inconstitucionais, não favorecendo, portanto, a impunidade dos violadores de direitos humanos.

Mezarobba (2007) considera a anistia brasileira como uma "conciliação pragmática", a qual contribuía com a transição para o regime democrático. Por outro lado, essa transição é considerada um remetente ao esquecimento, deixando de lado (ou melhor, não objetivando alcançar) aspectos fundamentais para a justiça de transição, como a busca da verdade, ou seja, "a revelação das circunstâncias em torno dos crimes e os nomes dos envolvidos" (MEZAROBBA, 2007, p. 14). A anistia brasileira é classificada por Santos (2010) como "anistia em branco", cujo objetivo é retirar (ou até mesmo não permitir) a responsabilidade de qualquer crime cometido, num determinado período, por indivíduos em nome do Estado.

Desse modo, não é difícil perceber que as autoanistias ferem o direito à verdade e à justiça, etapas essenciais para que se complete o processo de justiça de transição. Os "efeitos perversos [das leis de anistia] [...], permeiam todo o corpo social, com a consequência da perda da fé na justiça humana e nos verdadeiros valores, e uma perversa distorção dos fins do Estado". (SANTOS, 2010, p. 154)

\section{Poder Judiciário e (in)constitucionalidade da Lei de Anistia - análise da estrutura, do funcionamento e das prerrogativas do Poder Judiciário de ambos os países}

O Poder Judiciário obteve funções diferentes no momento da ditadura militar de cada um desses países. No Brasil, houve uma democracia aparente, a qual fazia com que grande parte da população não soubesse das atrocidades cometidas pelos agentes repressores e, dada a continuidade de aspectos democráticos, o regime demonstrava-se temporário, com vistas à manutenção econômica do país, conforme já foi exposto. 
As eleições diretas para o Congresso mantiveram-se, inclusive como forma de controlar as elites regionais. As regras dessas eleições eram alteradas de modo a permitir que os estados em que o partido do regime tivesse mais votos fossem vitoriosos e o regime não saísse do controle dos militares. Assim, a institucionalização da ditadura militar brasileira, tal como a continuidade do uso do discurso de democracia, era uma maneira de garantir legitimidade social ao regime. (TRIBESS, 2012; FAUSTO; DEVOTO, 2004)

O fato de a ditadura brasileira ter se preocupado mais com sua legitimação perante a sociedade fez com que ela resignificasse e adaptasse as instituições já existentes de acordo com suas intenções. A manutenção do Congresso, do Poder Judiciário e das eleições, mesmo que apenas de fachada, além de legitimar a ditadura, conseguiu aglomerar forças políticas e organizar o cotidiano político. Enquanto isso, o regime argentino tentou criar novas instituições que, de acordo com O'Donnell (1988), foram fracas e pouco efetivas para o governo.

A existência de julgamentos e eleições resultou numa legitimidade essencial, não só para o regime em si, mas também para o controle político que os militares obtiveram sobre a transição. Por outro lado, na Argentina não havia nenhuma espécie de julgamento e os presos simplesmente sumiam, aumentando a instabilidade social perante o regime. Mezarobba (2007) aponta que a estratégia de sumir com os presos políticos foi adotada pelas Juntas Militares desde o início do regime e disseminou o medo em toda a sociedade. Essa estratégia criava o que a autora nomeia de "não pessoas", havendo o intuito de confundir as organizações guerrilheiras e evitar que as vítimas se transformassem em heroínas perante a população, o que, para além, conferiu uma imagem de onipotência ao governo militar.

Desse modo, o grau de interação entre as elites militares e judiciárias era fundamental para definir o papel destas. Pereira (2010) argumenta que o consenso entre as elites era mais firme no Brasil e mais instável na Argentina, o que, de certo modo, explica as diferenciações entre os dois países nas questões do Poder Judiciário e dos julgamentos de presos políticos.

A caracterização mais incisiva do aparato repressor (cassações, torturas, assassinatos e prisões) no regime argentino é bastante clara, sobretudo em relação ao regime brasileiro. Entretanto, conforme Fausto 
e Devoto (2004), o regime ditatorial brasileiro buscou se mostrar como uma democracia restrita, a qual faz com que muitos chamem o regime brasileiro de "ditabranda". Os atos repressivos na ditadura argentina foram cometidos à margem da Lei e do Poder Judiciário, fato que demonstra sua intensidade, em especial quando comparados aos praticados no Brasil. (PEREIRA, 2010)

Porém, sabe-se que o regime brasileiro usou de diversos órgãos, como o Departamento de Ordem Política e Social (DOPS) e o Destacamento de Operações de Informações - Centro de Operações de Defesa Interna (DOI-CODI), para a prática de tais atos. Contudo, a institucionalização do regime fez com que suas práticas tivessem aparência menos nociva. Isso se explica, ainda, pelo uso de eleições e cargos para controlar as elites, conforme supracitado. No caso argentino, esses cargos eram disputados pelas Forças Armadas, de modo que a repressão foi mais forte como forma de aquietar as bases sociais. (TRIBESS, 2012)

A ausência de toda e qualquer forma democrática na Argentina impossibilitava o diálogo com a oposição, percebido, no Brasil, pelo bipartidarismo, importante meio de controle da oposição e, portanto, de redução do vácuo político que resultou de um isolamento do governo em relação à sociedade. A falta desse controle da oposição contribuiu para a continuidade do acirramento ideológico argentino, surgido no peronismo, com forte atuação de guerrilhas urbanas e com o discurso e a ação política muito mais radicalizados por ambos os lados - tanto do opositor quanto do regime propriamente dito. (LAMOUNIER, 1988; FAUSTO; DEVOTO, 2004)

Por conseguinte, conclui-se que as respectivas ditaduras atribuíram para si, cada qual a sua maneira, poderes de exceção. Nesse sentido, Pereira escreve:

Os governantes assumem o poder de forma inconstitucional, conferem a si próprios poderes de exceção para lidar com uma suposta situação de emergência e permanecem no poder por quanto tempo lhes parecer conveniente, uma vez que apenas eles têm competência para revogar os poderes de exceção. (PEREIRA, 2010, p. 26-27)

No caso brasileiro, a interação entre Poder Judiciário e poder militar resultou no que era ansiado pelos militares: o esquecimento e a impunidade. 


\section{Decisão dos poderes judiciários brasileiro e do argentino sobre a constitucionalidade da Lei de Anistia}

A Lei de Anistia brasileira, conforme já exposto, foi instrumento utilizado pelos militares do regime como forma de evitar o julgamento dos que haviam violado os direitos humanos e as liberdades democráticas. No ano de 2010, a pedido da Ordem dos Advogados do Brasil (OAB), foi julgada, numa Arguição de Descumprimento de Preceito Fundamental, a ADPF 153, pelo Supremo Tribunal Federal, e, nesse contexto, considerada como constitucional.

Consideraram, no julgamento da ADPF, alguns pontos para validar a lei, entre eles: i) anistia, mesmo dos que cometeram crimes nos porões da ditadura, enquanto preço que a sociedade pagou para acelerar a retomada pacífica, ou seja, defesa de uma transição conciliada; ii) anistia em termos de direito penal, não de responsabilidade do Estado, que deveria, portanto, ser convocada de modo a informar que não sejam esquecidos os horrores cometidos na ditadura brasileira; iii) abrogação da anistia em toda sua plenitude conduziria a insuportáveis consequências financeiras para os anistiados que receberam indenizações do Estado, os quais deveriam restituir os cofres públicos.

Durante o julgamento, foi, entretanto, muito ressaltada a ideia de repúdio às ações repressivas e aos excessos cometidos no regime militar, assim como a de que a não inconstitucionalidade da Lei de Anistia não implicava na impossibilidade de reconstituição da memória nacional a respeito do assunto. Dessa forma, os ministros e ministras presentes demonstraram levar em consideração apenas a memória no processo de justiça de transição, enquanto processos judiciais contra os violadores de direitos humanos não cabiam no contexto devido à Lei de Anistia.

Nesse sentido, como assinala Lúcia Elena Bastos (2007) e Mezarobba (2007), por se tratar de uma lei como outra qualquer, a anistia é "suscetível, pois, de execução pelo poder competente e sujeita a exame pelo Judiciário, se assim requererem os interessados, não satisfeitos ou mesmo prejudicados pela lei" (BASTOS, 2007, p. 29). Por isso, são absolutamente compreensíveis as divergências no entendimento da lei, em especial pela legitimação do regime ocorrida no Brasil e pela noção de que a anistia brasileira foi desejada e considerada um direito pelos perseguidos políticos.

Na Argentina, no julgamento da Lei de Pacificação Nacional, cujo texto assemelha-se ao da Lei de Anistia brasileira, o Poder Judiciário teve atitude completamente diferente e usou dessa possibilidade de 
interpretação de maneira também oposta à do Brasil. Muitos juizados e pelo menos uma Corte de apelações já haviam declarado a anistia inexistente como lei ou como sendo inconstitucional, antes mesmo de ela ter sido declarada nula por Alfonsín. Além disso, o judiciário argentino passou a considerar como sequestro permanente vários dos desaparecimentos ocorridos no período contemplado pela anistia, ou seja, entre 1973 e 1978 - enquanto, no Brasil, os que se enquadravam nessa situação foram dados como mortos. (MEZAROBBA, 2007; SANTOS, 2010)

Outro aspecto primordial foi a busca argentina pela punição dos violadores de direitos humanos pela legislação internacional, tal como a procura de subterfúgios na legislação nacional a fim de promover algumas causas judiciais. Porém, é importante ressaltar que, diferentemente do Brasil, as normas internacionais têm hierarquia constitucional desde 1994 na Argentina, o que de certo modo facilitou a ajuda de tribunais e cortes internacionais (como a Corte Interamericana de Direitos Humanos) e a punição dos envolvidos. A Constituição brasileira, apesar de prezar pelos direitos humanos, não mencionava diretamente a validade dos tratados internacionais até as emendas constitucionais de 2004 ao artigo $5^{\circ}, \S \S 2^{\circ}$ e $3^{\circ}$. Desse modo, conforme aponta Mezarobba (2007), à época, competia ao Supremo Tribunal Federal definir as incertezas sobre a validade de tratados internacionais, declarando ou não sua constitucionalidade de acordo com seu entendimento.

A influência do direito internacional no Poder Judiciário argentino foi determinante, também, para que as leis de Ponto Final e de Obediência Devida fossem tidas como inconstitucionais, o que já havia sido reconhecido por decisões da Comissão e Corte Interamericanas de Direitos Humanos (SANTOS, 2010). Nesse sentido, Naomi Roht-Arriaza (2002, p. 22) e Mezarobba (2007) argumentam que a indicação a tribunais internacionais "não apenas [altera] os limites do possível, mas também [coloca] o país sob escrutínio internacional, provocando reações [...] e [revitaliza] movimentos contra a impunidade".

Por conseguinte, tem-se que o Poder Judiciário argentino fez com que valesse a etapa transicional que se refere à punição dos militares, em especial dada sua consideração pelo direito internacional, que, conforme visto, foi fundamental enquanto mais uma forma de pressão política para o regime (que já se encontrava deslegitimado socialmente). Além disso, não se pode deixar de destacar a demanda popular pela Lei de Anistia no Brasil, que fez com que o entendimento do Poder Judiciário, ainda hoje, desse apoio enquanto concessão para uma transição pacífica e imediata 
- o que, entretanto, sabe-se não condizer com a realidade, uma vez que a lei não foi aprovada nos termos sugeridos pelas emendas propostas pela população.

\section{Conclusão}

A história foi, por muito tempo, se é que ainda não o é, contada de maneira eurocêntrica, ou seja, de acordo com os entendimentos e experiências europeias. Por essa razão, a experiência europeia (com o passar do tempo, também a norte-americana) foi tomada por muitos, inclusive por estudiosos, como a correta e como parâmetro para análise de (sub)desenvolvimento - como se a história se resumisse à ação de se chegar no mesmo patamar em que os países ditos desenvolvidos chegaram. (BARKAWI; LAFFEY, 2006)

A experiência das ditaduras do Cone Sul, assim como seus respectivos processos transicionais, coloca em voga a urgência desses países em enfrentar seus passados e em recontá-los de sua maneira para seus povos e para o mundo. Tendo em vista tal entendimento, viu-se, ao longo deste trabalho, a especificidade de ambos os momentos: o ditatorial, marcado pela represália da oposição, e o de transição, em que a influência daquele primeiro momento acaba por gerar peculiaridades neste segundo.

Mezarobba coloca as diversas esferas que a justiça de transição inclui:

processos judiciais contra acusados de violações de direitos humanos, que podem ocorrer na esfera doméstica, internacional ou mesmo desenvolver-se de forma híbrida [como foi no caso argentino, explicitado anteriormente]; a revelação da verdade; a adoção de medidas de reparação (não apenas financeiras); as reformas institucionais (que vão de expurgos no aparato estatal a transformações profundas em instituições como o Judiciário); a promoção de reconciliação entre as principais partes envolvidas no conflito e a preservação da memória do período, por intermédio da instalação, por exemplo, de museus ou monumentos. (2007, p. 20)

Posto isso, é notável que, no caso brasileiro, houve um desfalque em alguns desses aspectos (o direito à justiça, o direito à verdade, o direito à compensação e o direito a instituições reorganizadas), como no que tange ao direito à memória e à verdade, em especial se analisarmos a instalação tardia da Comissão da Verdade no país, que ocorreu apenas em meados de 2012. Apesar disso, é essencial ressaltar - tal como foi feito neste artigo - que não se pode simplesmente comparar os esforços de justiça de transição de ambos os países para, então, classificar um como melhor ou 
pior que o outro. Cada qual enfrentou diferentes barreiras para que fosse possível chegar ao contexto em que chegaram e, obviamente, alcançaram diferentes resultados.

Assim, a nomeação do regime como uma "ditabranda" mostra-se errônea, uma vez que a busca incessante pela institucionalização do regime fez com que este tentasse acobertar as atrocidades cometidas no período, especialmente as vistas nos órgãos DOPS e DOI-CODI. Além disso, a tradicional comparação numérica com o regime argentino, em especial no que se refere ao número de pessoas mortas, é também, complicada, de ser feita: as torturas feitas pelos ditadores aos opositores do regime, que muitas vezes não eram mortos, deixaram sequelas psicológicas nas vítimas e em suas famílias, o que tem sido evidenciado com os recentes testemunhos organizados pela Comissão Nacional da Verdade.

Desse modo, reafirmando a unicidade da história argumentada no início deste tópico, é fundamental perceber que o aparente sucesso econômico e a institucionalização da ditadura brasileira são alguns fatores que tornam mais claros os motivos das especificidades brasileiras, abordadas durante todo o artigo. Entende-se, por outro lado, que isso não é motivo para a acomodação, de forma que as atuais atividades da Comissão da Verdade, mesmo enfrentando diversas críticas quanto a seus resultados, fazem-se fundamentais como forma de não permitirem a perpetuação do esquecimento, que há muito vinha sendo cultivado nas mentes brasileiras.

O exercício de memória é importante não apenas para os que estudam o tema envolvido. Pereira se refere a isso como:

uma grave advertência feita aos cidadãos das democracias, alertando-os de que também seus direitos podem ser demolidos aos poucos, através de leis, ordens executivas e procedimentos administrativos adotados um de cada vez. (2010, p. 294)

Por conseguinte, a frase "para que não se esqueça, para que nunca mais aconteça" sintetiza o valor da justiça de transição - nos âmbitos social e político, em especial -, processo fundamental para a consolidação da democracia. 


\title{
Brazilian (1979) and Argentinian (1983) amnesty laws in a comparative perspective
}

\begin{abstract}
This paper discusses the transitional justice in Brazil and Argentina by analyzing their respective amnesty laws and their contexts of creation. This analysis is necessary to understand why the two processes had disparate ways, especially regarding the punishment of military personnel involved in the regime and in their atrocities. It will be discussed throughout the text about the legitimacy that the Brazilian dictatorship Brazilian obtained before the society and the use of it to provide a controlled transition, in opposition to what is perceived in the Argentine case. Accordingly, the present study shows a demonstration of the process of democratization in Brazil, which still pervades the present days and the need to strengthen its national memory so it will be consolidated in its totality.
\end{abstract}

Keywords: Dictatorship. Amnesty Law. Argentina. Brazil. Transitional justice.

\section{REFERÊNCIAS}

BARKAWI, Taraki; LAFFEY, Mark. The postcolonial moment in security studies. Review of International Studies, 2006.

BASTOS, Lúcia Elena Arantes Ferreira. Anistia: as leis internacionais e o caso brasileiro. Curitiba: Juruá, 2009.

. As leis de anistia face ao direito internacional: o caso brasileiro. 2007. Tese (Doutorado)-Faculdade de Direito, Universidade de São Paulo (USP), São Paulo, 2007.

FAUSTO, Boris; DEVOTO, Fernando J. Brasil e Argentina: um ensaio de história comparada. São Paulo: Editora 34, 2004.

GREIFF, Pablo de. Addressing the past: reparations for gross human rights abuses. In: Repairing the past: confronting the legacies of slavery, genocide \& caste - Proceeding of the Seventh Annual Gilder Lehrman Center International Conference at Yale University, New Haven (CT), 27 a 29 de out. de 2005. (Paper) 
LAMOUNIER, Bolívar. O "Brasil autoritário" revisitado: o impacto das eleições sobre a abertura. In: STEPAN, Alfred (Org.). Democratizando o Brasil. Rio de Janeiro: Paz e Terra, 1988.

MARTINS, Luciano. A "liberalização" do governo autoritário no Brasil. In: O'DONNELL, G., SCHMITTER, P. \& WHITEHEAD, L. (Org.). Transições do regime autoritário: América Latina. São Paulo: Vértice, 1988.

MEZAROBBA, Glenda. O preço do esquecimento: as reparações pagas às vítimas do regime militar. 2007. Tese (Doutorado em Ciência Política, área de concentração em Direitos Humanos)-Departamento de Ciências Políticas da Faculdade de Filosofia, Letras e Ciências Humanas, Universidade de São Paulo, São Paulo, 2007.

. Um acerto de contas com o futuro: a anistia e suas consequências - um estudo do caso brasileiro. 2003. Dissertação (Mestrado em Ciência Política)-Faculdade de Filosofia, Letras e Ciências Humanas, Universidade de São Paulo, São Paulo, 2003.

MINOW, Martha. Breaking the cycles of hatred: memory, law, and repair. Princeton: Princeton University Press, 2002.

NOVARO, Marcelo; PALERMO, Vicente. A Ditadura militar argentina 1976-1983: do golpe de Estado à restauração democrática. São Paulo: Unesp, 2007.

O'DONNELL, Guillermo; SCHMITTER, Philippe; WHITEHEAD, Laurence. Transições do regime autoritário: comparações e perspectivas. São Paulo: Vértice, 1988.

PEREIRA, Anthony W. Ditadura e repressão. São Paulo: Paz e Terra, 2010.

ROTH-ARRIAZA, Naomi. The Pinochet precedent and universal jurisdiction. New England Law Review, Boston, v. 35, n. 2, p. 311-319, winter 2001. 
SANTOS, Roberto Lima. Crimes da ditadura militar: responsabilidade internacional do estado brasileiro por violação aos direitos humanos. Porto Alegre: Núria Fabris, 2010.

TRIBESS, Camila. Considerações teóricas sobre as transições políticas no Brasil e na Argentina. 2012. Dissertação (Mestrado em Ciência Política)-Setor de Ciências Humanas, Letras e Artes, Universidade Federal do Paraná, Curitiba, 2012.

WEID, Gil de Souza Von Der. A farda e a toga - breve análise da relação entre os governos militares e o poder judiciário - comparação entre Brasil, Chile e Argentina. Revista Anistia Política e Justiça de Transição: Ministério da Justiça, Brasília, n. 6, 2012.

Recebido: outubro/2013. Aprovado: novembro/2013. 